\title{
The impact of the COVID-19 crisis on the perception of business risk in the SME segment
}

\author{
Martin Cepel \\ Faculty of Economics and Business, \\ Pan-European University in Bratislava, \\ Slovak Republic \\ martin.cepel@paneurouni.com
}

\section{Beata Gavurova}

Faculty of Management and Economics,

Tomas Bata University in Zlin,

Crech Republic

gavurova@utb.cr.

\section{Jan Dvorsky}

Faculty of Management and Economics,

Tomas Bata University in Zlin,

Crech Republic

dvorsky@utb.cz

\section{Jaroslav Belas}

Faculty of Management and Economics,

Tomas Bata University in Zlin,

Crech Republic

belas@utb.cz.

Abstract. The aim of the study is to evaluate the impact of the COVID-19 crisis on entrepreneurs' attitudes towards the selected business risks in the SME segment. 1502 SMEs took part in the research, while 822 of them provided their responses regarding business risks before the COVID-19 crisis and 680 during the COVID19 crisis in Czech and Slovak business environment. Market, financial, and personnel risks were considered by Czech SMEs as the three most significant business risks, both before and after the COVID-19 crisis. The statistically 
Slovakia. Before the crisis, up to $67.8 \%$ SMEs in Czech Republic and $62.8 \%$ in Slovakia considered personnel risk as one of the three most significant business risks. During the crisis, it was only $27.2 \%$ in Czech Republic and $29.4 \%$ in Slovakia.

Keywords: business environment, small and medium-sized enterprises, COVID-19 crisis, business risk, crisis scenario.

JEL Classification: D24, H32, D14

\section{INTRODUCTION}

The COVID-19 pandemic has significantly affected European and non-European enterprises. Millions of enterprises have lost their planned revenues, and millions of work positions have been compromised. The economic mechanism does not allow a shutdown of processes without an impact on the future of enterprises, and when the economy stops, many business ties cease, temporarily or permanently. The crisis also has a dramatic socioeconomic impact, as a large part of the population becomes poor, cannot pay for housing, loses jobs, houses, which leads to health issues and depression, and thus to higher mortality rate on the global scale. Problems of individuals become the problem of the entire society. Czech Republic and Slovakia are open economies and it is therefore crucial for the business ties between enterprises and business partners to remain intact. While international demand resumes, it is imperative for enterprises to be able to immediately resume production and get back to their previous routine. Many enterprises will no longer be able to do so. Unemployment statistics shows a significant growth on the global scale. The COVID-19 crisis has influenced the development of the global economy and threatened enterprises worldwide, as all economies were disrupted with fatal consequences. Many business segments were disconnected from the economy, office-based work changed to home office with the aim to ensure social distancing. Many job profiles were changed in order to cover critical functions and thus help maintain the health of economic systems.

SMEs were the ones most exposed to the risks resulting from the pandemic. Many countries intensively worked on adopting various measures of both financial and non-financial support such as direct financing, tax stimuli, financial guarantees, tax reliefs, loans on operating capital at a lower interest rate, etc. According to the OECD statistics, SMEs account for 99\% of all enterprises in the OECD member countries and yield up to $50-60 \%$ of the added value in their economies. As of the OECD estimates, microenterprises and small enterprises with up to 50 employees account for up to $43 \%$ of all employees in the OECD countries. Mid-sized enterprises (having 50-249 employees) account for 16\% of the population employment (Levashenko \& Koval, 2020). Stemming from this segment differentiation, it can be assumed that those most affected were the firms operating in the following industries: transport, travel, agriculture production, fashion, and services. These very industries were extremely sensitive to the negative effects of COVID-19 due to their limited number of vendors, short delivery times, etc. The more these companies depended on the countries affected by COVID-19, the more vulnerable they became. Those operating in various regional chains where the disruption of business ties was not so critical or detrimental were less vulnerable. Countries adopted support measures to prevent temporary layoffs, i.e. reducing work time, creating alternative jobs and workplaces, adopting measures to protect self-employed people, etc. Many countries worked intensively on adopting measures aimed at helping SMEs via searching for new work modes and new markets, creating and implementing various mentoring programs and financial seminars. Activities aimed at ensuring that SMEs are provided more information to be able to prevent COVID-19's negative effects were and still are 
essential. Specialized agencies, bank agencies, entrepreneurship societies, etc. play an important role in this process. They are gradually being activated across many countries.

Despite the fact that both Czech Republic and Slovakia joined the European Union with the vision of reducing regional disparities in their economic and social environments, these disparities only deepened between the regions, counties, and provinces. The reason for many production and economic disparities on both regional and local levels are old: economic burden, numerous external and internal environment determinants, and the failures of regulative systems. This led to many negative consequences evident in frequency, availability of sources, as well as lower economic/business performance. The COVID-19 crisis is so intense and has such a strong economic impact on the entire business and the economic system that these negative aspects and the development of regional disparities in the SMEs' development can deepen even further. The downfall of enterprises or their switch to the so-called emergency economic mode with an uncertain vision (as the COVID-19 pandemic is not over yet) can result in unforeseen consequences for the economies and the entire European society. The two countries under our consideration have not prepared scenarios for crisis development in the business environment, and this has been leading to a delay in implementing government-issued measures aimed at supporting SMEs.

All of the above has become the motivation to conduct this research with the aim to discover the attitudes of SME entrepreneurs towards various types of business risks. Two neighboring countries took part in the research: Czech Republic and Slovakia. Comparative analysis has made it possible to evaluate the differences in Czech and Slovak entrepreneurs' attitudes and hence obtain views on the business environment's stability in both countries and their resilience in managing universal business risks. The importance of this study lies in the absence of a previous study conducted within Czech and Slovak business environments that would examine entrepreneurs' attitudes towards various types of business risk and their comparison.

\section{LITERATURE REVIEW}

Quite a few research teams have examined the impact of the COVID-19 crisis on the business sector and the countries' economy in the past months. It is apparent that concrete economic consequences and their causal ties cannot be quantified at this time, as the COVID-19 crisis is not yet over, even though countries gradually loosen their protective measures and companies are trying to return to their normal regimes. The significance of available research studies and institutional reports lies in the identification of the implications and the examination of the selected implication structures that require a relevant database. It is therefore essential to map all determinants affecting the change in the countries' business environment. All research studies that examined the implications resulting from previous economic crises connected their findings with important implications for relevant policy types. Studies examining the effects of the COVID19 crisis offer implications that have a special meaning for policies - policy makers are able to gain valuable insights about the creation of system processes in individual countries in order to eliminate the impact of the crisis, as well as instructions on how to implement anti-crisis measures in the financial or the social sphere. As this research focuses on the SME segment and the area of business risk, the following research studies and their results served as inspiration:

Rathore et al. (2020) examined the impact of government interventions during the COVID-19 crisis in the Indian manufacturing sector. The authors conducted their primary research in micro, small, and medium-sized enterprises with the aim of learning what business owners' expectations are during the crisis. The smallest companies considered the emergency government measures to be very strict. Up to $70 \%$ of these businesses stated that if the lockdown continues, they would not survive the crisis after three months. In their study, even Alves et al. (2020) state that small enterprises are very sensitive to a crisis, however, 
there are no instructions on how to deal with the long crisis caused by COVID-19. They conducted a qualitative analysis of small enterprises in China after the virus outbreak. The authors discovered that the sudden drop in market demand had the strongest negative effect on small enterprises in particular. At the same time, small and young enterprises are highly flexible in the reaction to a crisis, mainly thanks to less bureaucracy and a limited adherence to social responsibility. The examined businesses adopted flexible HR strategies during the pandemic, while also utilizing the strategy of diversifying products, market research, and enhancement of education. Small enterprises with a longer history and more experience in handling crises, operating predominantly in regulated industries, had a formal crisis plan and crisis strategies in place even before the pandemic outbreak. Enterprises' reactions to the implementation of innovative marketing strategies were also examined by Wang et al. (2020). Their goal was to find out how Chinese enterprises innovate their marketing strategies, focusing mainly on innovation motivators and the evaluation of the level of innovations based on cooperation. Business risk in China is closely linked to political association and managerial power heterogeneity as the study of Chai and Sikandar Mirza (2019) shows. The study results provided interesting implications regarding enterprises' readiness for similar crisis situations. Fontrodona and Muller (2020) looked at the problem of COVID-19's impact on SMEs from the enterprises' social responsibility point of view. They draw attention to the adherence to ten principles of the Global Compact considered by authors as an appropriate tool for the evaluation of the level of consistency demonstrated by socially responsible societies during the pandemic. Besides monitoring the impact of the pandemic on business operations via research teams, many countries used monitoring via their government institutions with the aim of obtaining the most accurate relevant pictures about the situation in the business sector. Abebe et al. (2020) point out the importance of phone surveys conducted by the World Bank Ethiopia team. Their goal was to monitor the impact of the COVID-19 pandemic on the economy and the people in Ethiopia and inform about interventions and political reactions. Morales et al. (2020) point to the importance of bureaucratic effectivity during the COVID-19 crisis and emphasize the necessity for the creation of proper mechanisms of setting up optimal administrative processes for the time of crisis. The strong institutional impact of managing the COVID-19 crisis and its implications for the economy is apparent in the study of Redmond and McGuinness (2020). In their study, they emphasize the role of the Economic and Social Research Institute. Scientists from this institute focus on 12 critical areas for Ireland in the 21 st century. The authors use Irish Labor Force Survey data in their report to profile the characteristics of the necessary work positions during the pandemic. The authors also mention data limitations that hinder an exact specification of all necessary labor during a pandemic. Their study can serve as an important basis for the development of future crisis scenarios. Spain, as one of the most affected countries, was very sensitive in perceiving the political implications of the COVID-19 crisis, as shown in the study by Miguel et al. (2020). The authors analyzed the unequal political and economic burden of the Covid-19 crisis across Spanish households, and examined the extent to which knowledge about the crisis caused by the pandemic affected people's political beliefs and views. They also examined the extent to which knowledge about policies affected political views in the society. The authors emphasize the importance of information and knowledge about the pandemic's development and the ways of getting information, as well as the complexity level of the information that helps form views within the society and the population. Didier et al. (2020) studied the topic of financing firms in hibernation during the COVID-19 pandemic. They mention a strong negative impact of the pandemic on countries' economies worldwide and the suspension of business activities. They dispute the fact that the expectations regarding a problem-free functioning of companies after the pandemic can be very surprising. The authors state that companies have stopped cash flows, which can trigger inefficient bankruptcies with long-term detrimental effects. They list serious risks such as disruption of valuable relationships between enterprises and employees, governments and creditors, and the disruption of supply chains. The authors point out that financial systems are not ready to handle this type 
of exogenous and synchronized systemic shock. To conclude, they appeal to the countries' governments for a cooperation with financial sectors in order to ensure the firms' survival. The authors also believe that in order for the firms to survive, it is important to manage credit risk and implement policies with stimulating mechanisms. In a study conducted by the Khan et al. (2020) before the COVID-19, it was noted that the great number of entrepreneurs in Slovakia (about 43\%) expressed the opinion that bankruptcy is a natural phenomenon when doing business. Slightly less number of Czech entrepreneurs supported this point of view $(32 \%)$, while a large percentage of surveyed Czech owners or managers of SMEs believed that bankruptcy was a mistake of the entrepreneur (senior management of the company). At the same time, the authors note that bankruptcy can bring new analytical skills to the owners (and managers) of SMEs for competent risk management in the future (see also Adair \& Adaskou, 2018; Mostenska et al., 2015). During the COVID-19 pandemic, the role of bankruptcy changes as well. This fact is presented in the study by Morrison and Saaedra (2020) who claim that policy makers minimize the role of the bankruptcy law when reducing the financial impact of the COVID-19 pandemic. The authors emphasize that bankruptcy can be very expensive for small enterprises, which may deter them from filing for one. The authors also present the importance of key political tools - bridging financing and tolerating. The government should provide bridging financing when credit markets are non-functional. Courts of law also gain importance as bankruptcies are filed. The impact of the COVID-19 crisis on SMEs was also studied by Lu et al. (2020) whose aim was to evaluate issues regarding work recovery and corresponding political demands. Their research sample consisted of 4807 SMEs in the Sichuan Province, using surveys and online interviews as their research method. The majority of SMEs was unable to continue operating due to the shortage of epidemic mitigation materials, the inability of employees to return to work, disrupted supply chains, and reduced market demand. They listed cash flow risks as the main risks regarding SMEs' survival due to numerous fixed expenses, but only a low or no income. This generated a considerable push for SMEs' survival. The study also serves as an appeal for the creation of recommendations regarding work recovery, stimulation of consumption, and cash flow relief, all in order for SMEs to survive during the economic recovery followed by the COVID-19 pandemic. Prohorovs (2020) introduces the need for a clear understanding of the COVID-19 crisis' specifics, so that enterprises can adapt to the new situation faster while reducing damages. The author compares the current economic recession caused by the COVID-19 pandemic with previous economic crises. Being a business owner himself, he presents his own experience with reducing business risk caused by a pandemic. Financial performance in time of Covid-19 also varies across firms depending on ultimate owner risk aversion attitudes (Staszkiewicz \& Szelagowska, 2019). Methods firms' implement to monitor key risk indicators also proves important in time of pandemic crisis (Peček \& Kovačić, 2019).

The presented experience and recommendations should ensure SMEs' sustainability in these difficult business conditions. Many other studies offer recommendations for the micro and the macro-sphere. Wang et al. (2020) studied the topic of government support for SMEs followed by the outbreak of COVID-19, promoting the theoretical model of Wang's transformation. The authors present measures adopted by governments in order to support SMEs and reduce the economic impact of the COVID-19 pandemic. Their theoretical model is supposed to be essential for the evaluation of various government measures, including insurance for bank loans, interest rate subsidies, bridge loans and tax reliefs. The authors distinguish a firm's intrinsic value and book value, where a firm can lose its intrinsic value when it encounters a cash flow crunch. The authors emphasize the importance of providing bridging loans for SMEs during and after the pandemic, in order to eliminate mass shutdowns of SMEs. The authors conclude by presenting explicit political recommendations aimed at establishing politically-oriented banks or investments funds designed to support SMEs, analyze risks SMEs face, improve the acceptance of risk by financial institutions by providing long-term tax reliefs and investments for SMEs, etc. Financial aspects and research of relevant 
financial support tools for SMEs during a pandemic are the topic of the study by Levashenko and Koval (2020). The author claims that SMEs are much more exposed to pandemic risks than large companies are. They emphasize the implementation and use of financial tools such as direct financing, tax stimuli, etc. The system of non-financial support is also important, according to the author. Some research studies examined the impact of COVID-19 within business sectors. According to Hudson (2020a), travel and hospitality sector were two of the sectors most impacted by the COVID-19 crisis. The author draws attention to the fact that the majority of studies emphasize the economic aspects of the pandemic; however, this epidemic resulted not only in an economic crisis, but also has important social and environmental implications that severely affected the travel sector. These are examined in detail in the study by Hudson (2020b) who also mentions important policy implications, connecting sector-specific policy solutions with macroeconomic indicators. The examination of the impact of COVID-19 has a strong geographical undertone in some of the studies, e.g. in case of Åslund (2020) who studied the reactions to the COVID-19 crisis in Russia, Belarus, and Ukraine. These countries provide a suitable ground for comparison due to their common Soviet past, similar culture and religion. However, during the COVID-19 crisis, these countries implemented completely different policies, which showed in their economic results. By examining these countries, the author makes suitable comparisons in order to evaluate the impact of the implemented policies on the countries' economic results. He claims that the impact cannot be quantified at this time, as they will show in the countries' key economic parameters later on. Michie (2020) creates his own philosophical framework of evaluating the implications of the COVID-19 crisis for national economies, stemming from macroeconomic aspects. He questions whether the adopted measures and the preparations for the crisis whose onset had been discussed in advance were sufficient, and how the recession will affect mortality and morbidity in form of a deterioration of physical and mental health, increased number of suicides, etc. The author states that there will always be economic arguments used by politicians to defend their reactions to a recession in order to implement saving measures aimed at decreasing national debt, etc. This can lead to a higher mortality in countries. He claims that three attributes remain very important during a crisis: the economy, economics, and economic policy. Exogenous economic shocks, oil price shocks, economic policy uncertainty, geopolitical risk exercise a strong impact on stock market that we can compare with the pandemic impact for benchmarking pandemic impact (Enamul Hoque et al., 2019).

Despite their diversified geographical orientation and their different SME research samples, the above mentioned research studies provide valuable information about the business segment and the problems SMEs face during the COVID-19 crisis, as well as inspiration on how to eliminate the negative economic consequences for the SME segment in many countries. The presence of a strong research platform on this topic is apparent, allowing new research partnerships to be formed that would monitor economic and noneconomic aspects of the crisis in a timely manner and prepare adequate crisis scenarios. This would help not only SMEs, but also many government structures in setting stabilizing and regulative mechanisms aimed at reviving and support of the SME segment in the future.

\section{METHODOLOGY}

The aim of the study was to evaluate the impact of the COVID-19 crisis on entrepreneurs' notions towards selected business risks in the SME segment. The study was conducted in the Czech Republic and Slovakia, which ensured an adequate comparative platform supported by the historical connection of the two countries. The research of the business environment in both countries was conducted between 09/2019 and $02 / 2020$, at the time of the economies' unfavorable development. The strong negative impact of the COVID-19 crisis inspired a subsequent research during the COVID-19 crisis accompanied by a significant economic insecurity $(5 / 2020)$. In total, a 100\% of responses were collected from 1502 respondents: 822 
(54.7\%) before the COVID-19 crisis and 680 (45.3\%) during the COVID-19 crisis. The universal register of firms, organizations and self-employed persons called CRIBIS was used to obtain information about business subjects in the Czech Republic and Slovakia. Respondents were chosen using the method of random selection and asked by email to fill out an online questionnaire. The questionnaires are available in the two national languages on the following websites:

- Slovak version: https://forms.gle/rzX3qYeqrcqRFeAF6

- Czech version: https://forms.gle/okjZypAru4BpSHFb8

In total, 8,250 SMEs were approached in the Czech Republic and 10,100 in Slovakia. The response rate was 5.5\% in the Czech Republic and 3.6\% in Slovakia. The total number of received questionnaires was 465 in the Czech Republic and 372 in Slovakia. The number of properly filled out questionnaires (hereinafter selected set of data) was 454 respondents in the Czech Republic and 368 in Slovakia. The most common reasons for excluding a respondent from the selected set of data: questionnaire duplicates in the selected set of data; inconsistencies of respondents' notions towards business risk; respondents' lack of attention to those questions that should not have answered, etc. The collection of data took place from 11.5.2020 until 17.5.2020 using an online method by the Czech and Slovak panel of MNFORCE. The selected set of data of the respondents after COVID19 consisted of 680 SMEs. Out of the total number of respondents, 360 $(52.9 \%)$ were from the Czech Republic and 320 (47.1\%) from Slovakia.

The following claims regarding business risk and the threat of business decline were formulate in order to reach the main aim of the study:

ST1: Which business risk do you consider the most important? Name a maximum of three.

ST2: I evaluate market risk (lack of sales for my enterprise) as adequate.

ST3: I evaluate the financial performance of our (my) enterprise as positive.

ST4: I can manage financial risk in my (our) enterprise adequately.

ST5: I evaluate personnel risk as adequate, not having a negative impact on my business.

ST6: Our (my) enterprise does not face a threat of decline within the next 5 years.

Respondents had the opportunity to name a maximum of three business risks in case of ST1. The ST2ST6) were formulated in such a way that the respondents had to answer using one of the following options: (A1) I fully agree, (A2) I agree, (A3) I neither agree nor disagree, (A4) I disagree, (A5) I fully disagree.

Statistical hypotheses were formed in order to reach the main aim of the study:

H1: There are no statistically significant differences in the structure of responses regarding claims ST1 (H1_ST1), ST2 (H1_ST2), ST3 (H1_ST3), ST4 (H1_ST4), ST5 (H1_ST5), and ST6 (H1_ST6) among the respondents before the COVID19 pandemic and at the time of the COVID19 pandemic's peak in the Czech SMEs' business environment.

$\mathrm{H} 2$ : There are no statistically significant differences in the structure of responses regarding claims ST1 (H2_ST1), ST2 (H2_ST2), ST3 (H2_ST3), ST4 (H2_ST4), ST5 (H2_ST5), and ST6 (H2_ST6) among the respondents before the COVID19 pandemic and at the time of the COVID19 pandemic's peak in the Slovak SMEs' business environment.

H3: There are no statistically significant differences in positive notions (A1+A2) regarding claims ST2 (H3_ST2), ST3 (H3_ST3), ST4 (H3_ST4), ST5 (H3_ST5), ST6 (H3_ST6) among the respondents before the COVID19 pandemic and at the time of the COVID19 pandemic's peak in the Czech SMEs' business environment.

H4: There are no statistically significant differences in positive notions (A1+A2) regarding claims ST2 (H4_ST2), ST3 (H4_ST3), ST4 (H4_ST4), ST5 (H4_ST5), ST6 (H4_ST6) among the respondents before 
the COVID19 pandemic and at the time of the COVID19 pandemic's peak in the Slovak SMEs' business environment.

Pearson's Chi-square test was applied to discover statistically significant differences among the selected groups of respondents based on the set criteria (verification of statistical hypotheses H1 and H2). The first step within the statistical method is the utilization of descriptive statistics (descriptive characteristics absolute and relative frequency). To determine the descriptive characteristics, the method of simple sorting was used - sorting based on two statistical characters (research criterion; type of response). The results are presented in the contingency tables (see Table 2 - Table 6). To calculate the TK for Pearson's Chi-square test, it is necessary to calculate also the expected (theoretical) frequency (Agresti, 1992). In order to apply the Pearson's Chi-square test, it is necessary for all respondent groups to meet the minimum expected frequency of 5 (Goodman, 1970). If the calculated p-value of the testing criterion is higher than the level of significance, then the null hypothesis on the change of the overall structure of respondents' notions cannot be rejected. The test strength (Goodman, 1970; Wallis, 2013) depends on the ratio of actual and expected frequencies. The higher the number of respondents in a group, the higher the test reliability (Baglivo et al., 1988). The z-score method was used to discover statistically significant differences in respondents' positive notions $(\mathrm{A} 1+\mathrm{A} 2)$ based on the selected criterion. If $\mathrm{p}$-value of the $\mathrm{z}$-score method is higher than the level of significance $(\alpha=0.05)$, then the null hypothesis cannot be rejected. All calculations were done using the SPSS Statistics statistical software and MS Excel.

The basic structure of respondents: Czech Republic before the pandemic/Czech Republic after the pandemic/Slovak Republic before the pandemic/Slovak Republic after the pandemic (454/360/368/320): Business size: 290/171/216/201 micro-enterprises (up to 9 employees), 107/75/106/61 small enterprises (from 10 to 49 employees), 7/114/46/58 medium-sized enterprises (from 50 to 249 employees); Legal form of the business: 135/152/59/161 self-employed, 266/116/266/113 Ltd., 34/63/21/25 joint stock company, 19/29/22/21 other type of legal form; Industry: 79/61/70/40 manufacturing, 91/83/76/78 trade, $63 / 35 / 41 / 26$ construction, 10/20/10/15 transport, $11 / 5 / 8 / 6$ agriculture, $11 / 14 / 15 / 6$ travel, $133 / 88 / 107 / 118$ services, 56/54/41/31 other industry; Length of operating a business: 55/112/53/107 up to 5 years, 64/65/52/77 from 5 to 10 years, 335/183/263/136 more than 10 years; Respondent's gender: $323 / 181 / 253 / 172$ men, 131/179/115/148 women; Highest attained education of the respondent: 46/51/13/31 high school without leaving exam, 185/184/64/165 high school with leaving exam, 34/42/21/26 Bachelor's degree, 168/66/234/84 Master's degree, 21/17/36/14 Doctorate degree; Age of respondents: 69/118/66/105 up to 35 years,106/109/79/96 from 36 to 45 years, 122/71/106/81 from 46 to 55 years, $157 / 62 / 117 / 38$ aged 55 and higher; Respondents' status within the enterprise: 354/172/285/192 business owner; 100/188/83/128 business manager.

\section{EMPIRICAL RESULTS AND DISCUSSION}

The entire sample of respondents' notions towards the ST1 claim was distributed as follows: 1362/1104 responses in the Czech Republic/Slovakia before COVID-19 and 1080/960 responses in the Czech Republic/Slovakia after COVID-19. The respondents expressed their notions 1055 (77.4\%)/837 (75.8\%) times in the Czech Republic/Slovakia before COVID-19 and 699 (64.7\%)/660 (68.7\%) times in the Czech Republic/Slovakia after COVID-19. These results indicate that the respondents took advantage of the possibility to provide more than one answer to the given question. Table 1 shows absolute and relative frequency of selected business risks described by the respondents as the most important. 
Table 1

Evaluation of the most important business risks

\begin{tabular}{|c|c|c|c|c|c|c|c|c|}
\hline \multirow{3}{*}{$\begin{array}{l}\text { Type of risk } \\
\text { Strategic risk }\end{array}$} & \multicolumn{4}{|c|}{ Czech Republic } & \multicolumn{4}{|c|}{ Slovak Republic } \\
\hline & \multicolumn{2}{|c|}{ Before COVID-19 } & \multicolumn{2}{|c|}{ During COVID-19 } & \multicolumn{2}{|c|}{ Before COVID-19 } & \multicolumn{2}{|c|}{ During COVID-19 } \\
\hline & 86 & $18.9 \%$ & 49 & $13.6 \%$ & 67 & $18.2 \%$ & 50 & $15.6 \%$ \\
\hline Market risk & 267 & $58.8 \%$ & 216 & $60.0 \%$ & 201 & $54.6 \%$ & 196 & $61.3 \%$ \\
\hline Financial risk & 162 & $35.7 \%$ & 193 & $53.6 \%$ & 130 & $35.3 \%$ & 191 & $59.7 \%$ \\
\hline Personnel risk & 308 & $67.8 \%$ & 98 & $27.2 \%$ & 231 & $62.8 \%$ & 94 & $29.4 \%$ \\
\hline Legal risk & 161 & $35.5 \%$ & 68 & $18.9 \%$ & 157 & $42.7 \%$ & 60 & $18.8 \%$ \\
\hline Operating risk & 71 & $15.6 \%$ & 75 & $20.8 \%$ & 51 & $13.9 \%$ & 69 & $21.6 \%$ \\
\hline Number of respondents & \multicolumn{2}{|c|}{454} & \multicolumn{2}{|c|}{360} & \multicolumn{2}{|c|}{368} & \multicolumn{2}{|c|}{320} \\
\hline Chi-square (p-value) & \multicolumn{4}{|c|}{$96.449(0.000)$} & \multicolumn{4}{|c|}{$98.383(0.000)$} \\
\hline
\end{tabular}

Source: own data collection

The results in Table 1 indicate that while personnel risk was considered by the Czech respondents as one of the three most significant business risks before COVID-19 (67.8\%), only $27.2 \%$ of the respondents were of the same opinion during the COVID-19 crisis. Similar findings were made in the Slovak SME segment (dropping from $62.8 \%$ to $29.4 \%$ ). On the contrary, the number of respondents listing financial risk as one of the three most important business risks almost doubled in both the Czech Republic (35.7\%/53.6\%) and Slovakia $(35.3 \% / 59.7 \%)$.

The results confirmed the shift in the perception of the three most significant business risks due to the COVID-19 crisis in the Czech business environment ( $\mathrm{p}$-value $=0.000)$ and the Slovak business environment (p-value $=0.000)$. Hypotheses H1_ST1 and H2_ST1 were rejected. Table 2 shows respondents' notions towards market risk due to the lack of sales based on the chosen criterion.

Table 2

Evaluation of market risk

\begin{tabular}{|c|c|c|c|c|c|c|c|c|}
\hline \multirow{3}{*}{$\begin{array}{l}\text { ST2 } \\
\text { A1 }\end{array}$} & \multicolumn{4}{|c|}{ Czech Republic } & \multicolumn{4}{|c|}{ Slovak Republic } \\
\hline & \multicolumn{2}{|c|}{ Before COVID-19 } & \multicolumn{2}{|c|}{ During COVID-19 } & \multicolumn{2}{|c|}{ Before COVID-19 } & \multicolumn{2}{|c|}{ During COVID-19 } \\
\hline & 72 & $15.9 \%$ & 32 & $8.9 \%$ & 33 & $9.0 \%$ & 26 & $8.1 \%$ \\
\hline A2 & 187 & $41.1 \%$ & 174 & $48.3 \%$ & 145 & $39.3 \%$ & 152 & $47.5 \%$ \\
\hline A3 & 133 & $29.3 \%$ & 67 & $18.6 \%$ & 122 & $33.2 \%$ & 58 & $18.1 \%$ \\
\hline A4 & 39 & $8.6 \%$ & 77 & $21.4 \%$ & 58 & $15.8 \%$ & 71 & $22.2 \%$ \\
\hline A5 & 23 & $5.1 \%$ & 10 & $2.8 \%$ & 10 & $2.7 \%$ & 13 & $4.1 \%$ \\
\hline NR & 454 & $100 \%$ & 360 & $100 \%$ & 368 & $100 \%$ & 320 & $100 \%$ \\
\hline Chi-square & \multicolumn{4}{|c|}{$44.947(0.00001)$} & \multicolumn{4}{|c|}{$22.212(0.0002)$} \\
\hline
\end{tabular}

Note: NR - Number of respondents. Source: own data collection. 
The results in Table 2 indicate that the respondents' view the adequacy of business sales as more negative (A4: 8.6\% before COVID-19, A4: 21.4\% after COVID-19) in the SME segment in the Czech Republic and Slovakia (A4: 15.8\% before COVID-19, A4: 22.2\% after COVID-19). The results confirmed the change in respondents' notions towards the adequacy of the sale of products and services due to the COVID-19 pandemic in the Czech business environment at the level of significance $(\alpha=0.001)$, and in the Slovak business environment at the level of significance $(\alpha=0.001)$. Hypotheses H1_ST2 and H2_ST2 were rejected. Table 3 shows respondents' notions towards the financial performance of an enterprise (ST3) based on the chosen criterion.

Table 3

Evaluation of financial performance

\begin{tabular}{|l|c|c|c|c|c|c|c|c|}
\hline \multirow{2}{*}{ ST3 } & \multicolumn{4}{|c|}{ Czech Republic } & \multicolumn{4}{c|}{ Slovak Republic } \\
\cline { 2 - 9 } & Before COVID-19 & During COVID-19 & Before COVID-19 & \multicolumn{2}{c|}{ During COVID-19 } \\
\hline A1 & 105 & $23.1 \%$ & 27 & $7.5 \%$ & 64 & $17.4 \%$ & 21 & $6.6 \%$ \\
\hline A2 & 200 & $44.1 \%$ & 153 & $42.5 \%$ & 170 & $46.2 \%$ & 117 & $36.5 \%$ \\
\hline A3 & 103 & $22.7 \%$ & 92 & $25.6 \%$ & 76 & $20.7 \%$ & 94 & $29.4 \%$ \\
\hline A4 & 31 & $6.8 \%$ & 69 & $19.2 \%$ & 51 & $13.9 \%$ & 66 & $20.6 \%$ \\
\hline A5 & 15 & $3.3 \%$ & 19 & $5.2 \%$ & 7 & $1.8 \%$ & 22 & $6.9 \%$ \\
\hline NR & 454 & $100 \%$ & 360 & $100 \%$ & 368 & $100 \%$ & 320 & $100 \%$ \\
\hline Chi-square & \multicolumn{3}{|c|}{$57.796(0.00001)$} & & $39.974(0.00001)$ & \\
\hline
\end{tabular}

Note: NR - Number of respondents. Source: own data collection.

The results in Table 3 indicate that the COVID-19 crisis has a negative impact on the perception of the financial performance of an enterprise in the Czech SME segment (A4+A5: 10.1\% before COVID-19, A4+A5: 24.4\% after COVID-19) and the Slovak SME segment (A4+A5: 15.7\% before COVID-19, A4+A5: $27.5 \%$ after COVID-19). The results confirmed the change in respondents' notions towards the financial performance of an enterprise due to the COVID-19 pandemic in the Czech business environment ( $\mathrm{p}$-value $<0.001)$ and the Slovak business environment ( -value $<0.001)$. Hypotheses H1_ST3 and H2_ST3 were rejected. Table 4 shows respondents' notions towards the ability to manage financial risk (ST4) based on the chosen criterion.

Table 4

Evaluation of the ability to manage financial risk

\begin{tabular}{|l|c|c|c|c|c|c|c|c|}
\hline \multirow{2}{*}{ ST4 } & \multicolumn{4}{|c|}{ Czech Republic } & \multicolumn{4}{c|}{ Slovak Republic } \\
\cline { 2 - 9 } & Before COVID-19 & During COVID-19 & Before COVID-19 & \multicolumn{2}{c|}{ During COVID-19 } \\
\hline A1 & 116 & $25.6 \%$ & 38 & $10.6 \%$ & 72 & $19.6 \%$ & 24 & $7.5 \%$ \\
\hline A2 & 204 & $44.9 \%$ & 182 & $50.6 \%$ & 182 & $49.5 \%$ & 165 & $51.6 \%$ \\
\hline A3 & 106 & $23.3 \%$ & 96 & $26.7 \%$ & 89 & $24.2 \%$ & 83 & $25.9 \%$ \\
\hline A4 & 19 & $4.2 \%$ & 35 & $9.6 \%$ & 23 & $6.3 \%$ & 37 & $11.6 \%$ \\
\hline A5 & 9 & $2.0 \%$ & 9 & $2.5 \%$ & 2 & $0.4 \%$ & 11 & $3.4 \%$ \\
\hline NR & 454 & $100 \%$ & 360 & $100 \%$ & 368 & $100 \%$ & 320 & $100 \%$ \\
\hline Chi-square & \multicolumn{3}{|c|}{$35.616(0.00001)$} & & & $31.343^{*}(0.00001)$ & \\
\hline
\end{tabular}

Note: NR - Number of respondents; ${ }^{*}$ Joint group of A4+A5 to calculate the Chi-square test. Source: own data collection. 
The results in Table 4 indicate that the COVID-19 crisis has a negative impact on the ability to manage financial risk in the Czech SME segment (A4+A5: 6.2\% before COVID-19, A4+A5: 12.1\% after COVID19) and in the Slovak SME segment (A4+A5: 6.7\% before COVID-19, A4+A5: 15.0\% after COVID-19). The results confirmed the change in respondents' notions towards the ability to manage financial risk resulting from the COVID-19 crisis in the Czech business environment ( $\mathrm{p}$ - value $<0.001)$ and the Slovak business environment (p- value $<0.001$ ). Hypotheses H1_ST4 and H2_ST4 were rejected. Table 5 shows respondents' notions towards the adequacy of personnel risk and its negative impact on an enterprise (ST5) based on the chosen criterion

Table 5

Evaluation of the adequacy of personnel risk

\begin{tabular}{|l|c|c|c|c|c|c|c|c|}
\hline \multirow{2}{*}{ ST5 } & \multicolumn{4}{|c|}{ Czech Republic } & \multicolumn{4}{c|}{ Slovak Republic } \\
\cline { 2 - 9 } & Before COVID-19 & During COVID-19 & Before COVID-19 & \multicolumn{2}{c|}{ During COVID-19 } \\
\hline A1 & 61 & $13.4 \%$ & 38 & $10.6 \%$ & 48 & $13.0 \%$ & 26 & $8.1 \%$ \\
\hline A2 & 170 & $37.4 \%$ & 165 & $45.8 \%$ & 122 & $33.2 \%$ & 136 & $42.5 \%$ \\
\hline A3 & 115 & $25.4 \%$ & 98 & $27.2 \%$ & 98 & $26.6 \%$ & 72 & $22.5 \%$ \\
\hline A4 & 70 & $15.4 \%$ & 43 & $11.9 \%$ & 82 & $22.3 \%$ & 70 & $21.9 \%$ \\
\hline A5 & 38 & $8.4 \%$ & 16 & $4.5 \%$ & 18 & $4.9 \%$ & 16 & $5.0 \%$ \\
\hline NR & 454 & $100 \%$ & 360 & $100 \%$ & 368 & $100 \%$ & 320 & $100 \%$ \\
\hline Chi-square & \multicolumn{3}{|c|}{$11.487(0.022)$} & & & $9.037(0.060)$ \\
\hline
\end{tabular}

Note: NR - Number of respondents.

Source: own data collection.

The results in Table 5 indicate that the COVID-19 crisis has a positive impact on respondents' notions towards the adequacy of personnel risk in the Czech SME segment (A1+A2: 50.8\% before COVID-19, A1+A2: 56.4\% after COVID-19). The results confirmed the change in respondents' notions towards the claim regarding adequacy of personnel risk as a result of the COVID-19 pandemic in the Czech SMEs' business environment ( $p$-value $=0.022)$ at the level of significance $(\alpha=0.05)$. In the Slovak SME business environment, the respondents' views indicates a statistically insignificant impact of the COVID-19 pandemic on the perception of the adequacy of personnel risk $(\mathrm{p}$-value $=0.060)$. Hypothesis H1_ST5 was rejected. Hypothesis H2_ST5 cannot be rejected. Table 6 shows respondents' views on the threat of business decline within the next five years (ST6) based on the chosen criterion.

Table 6

Evaluation of the threat of business decline

\begin{tabular}{|l|c|c|c|c|c|c|c|c|}
\hline \multirow{2}{*}{ ST6 } & \multicolumn{4}{|c|}{ Czech Republic } & \multicolumn{4}{c|}{ Slovak Republic } \\
\cline { 2 - 9 } & \multicolumn{2}{|c|}{ Before COVID-19 } & \multicolumn{2}{|c|}{ During COVID-19 } & Before COVID-19 & \multicolumn{2}{c|}{ During COVID-19 } \\
\hline A1 & 138 & $30.4 \%$ & 67 & $18.6 \%$ & 75 & $20.4 \%$ & 40 & $12.5 \%$ \\
\hline A2 & 149 & $32.8 \%$ & 144 & $40.0 \%$ & 110 & $29.9 \%$ & 119 & $37.2 \%$ \\
\hline A3 & 112 & $24.7 \%$ & 86 & $23.9 \%$ & 126 & $34.2 \%$ & 104 & $32.5 \%$ \\
\hline A4 & 31 & $6.8 \%$ & 44 & $12.2 \%$ & 38 & $10.3 \%$ & 47 & $14.7 \%$ \\
\hline A5 & 24 & $5.3 \%$ & 19 & $5.3 \%$ & 19 & $5.2 \%$ & 10 & $3.1 \%$ \\
\hline NR & 454 & $100 \%$ & 360 & $100 \%$ & 368 & $100 \%$ & 320 & $100 \%$ \\
\hline
\end{tabular}




\begin{tabular}{|l|l|l|}
\cline { 2 - 3 } Chi-square & $20.341(0.00043)$ & $13.573(0.0088)$ \\
\hline
\end{tabular}

Note: NR - Number of respondents. Source: own data collection.

The results (see Table 6) indicate that the COVID19 pandemic has a negative impact on respondents' notions regarding the threat of business decline in the SME segment in the Czech Republic (A1: 30.4\% before COVID19, A1: 18.6\% after COVID19) and Slovakia (A1: 20.4\% before COVID19, A1: 12.5\% after COVID19). The results confirmed the change in respondents' notions towards the claim regarding threat of business decline as a result of the COVID19 pandemic in the Czech SMEs' business environment ( $\mathrm{p}$ value $=0.00043)$ and the Slovak SMEs' business environment $(\mathrm{p}$ - value $=0.0088)$. Hypotheses H1_ST6 and H2_ST6 were rejected. Table 7 shows the comparison of respondents' positive notions towards the selected claims (ST2 - ST6) based on the chosen criterion.

Table 7

Comparison of positive notions towards the selected claims

\begin{tabular}{|c|c|c|c|c|c|c|c|c|}
\hline \multirow{3}{*}{$\begin{array}{l}\mathrm{A} 1+\mathrm{A} 2 \\
\mathrm{ST} 2\end{array}$} & \multicolumn{4}{|c|}{ Czech Republic } & \multicolumn{4}{|c|}{ Slovak Republic } \\
\hline & \multicolumn{2}{|c|}{ Before COVID-19 } & \multicolumn{2}{|c|}{ During COVID-19 } & \multicolumn{2}{|c|}{ Before COVID-19 } & \multicolumn{2}{|c|}{ During COVID-19 } \\
\hline & 259 & $57.0 \%$ & 206 & $57.2 \%$ & 178 & $48.4 \%$ & 178 & $55.6 \%$ \\
\hline Z-score & \multicolumn{4}{|c|}{$-0.0498(0.96012)$} & \multicolumn{4}{|c|}{$-1.8996(0.05744)$} \\
\hline ST3 & 305 & $67.2 \%$ & 180 & $50.0 \%$ & 234 & $63.6 \%$ & 138 & $43.1 \%$ \\
\hline Z-score & \multicolumn{4}{|c|}{$4.9609(0.00000)$} & \multicolumn{4}{|c|}{$5.3719(0.00000)$} \\
\hline ST4 & 320 & $70.5 \%$ & 220 & $61.1 \%$ & 254 & $69.0 \%$ & 189 & $59.1 \%$ \\
\hline Z-score & \multicolumn{4}{|c|}{$2.8107(0.00496)$} & \multicolumn{4}{|c|}{$2.721(0.00652)$} \\
\hline ST5 & 231 & $50.9 \%$ & 203 & $56.4 \%$ & 170 & $46.2 \%$ & 162 & $50.6 \%$ \\
\hline Z-score & \multicolumn{4}{|c|}{$1.5644(0.1876)$} & \multicolumn{4}{|c|}{$-1.1597(0.24604)$} \\
\hline ST6 & 287 & $63.2 \%$ & 211 & $58.6 \%$ & 185 & $50.3 \%$ & 159 & $49.7 \%$ \\
\hline Z-score & \multicolumn{4}{|c|}{$-1.3389(0.18024)$} & \multicolumn{4}{|c|}{$0.1529(0.88076)$} \\
\hline
\end{tabular}

Source: own data collection

The results confirmed the change in respondents' positive notions towards financial risk (financial performance of SMEs (ST3) and the ability to manage financial risk (ST4) due to the COVID19 pandemic in the Czech business environment (ST3: p-value $=0.000 ;$ ST4: $\mathrm{p}$-value $=0.00496$ ) and in the Slovak business environment (ST3: p-value $=0.000$; ST4: p-value $=0.00652$ ). Hypotheses H3_ST3, H3_ST4, H4_ST3, and H4_ST4 were rejected. The impact of COVID19 was not confirmed in the remaining comparisons of respondents' notions towards the ST2, ST5, and ST6 claims (p-value > 0.05). Hypotheses H3_ST2, H3_ST5, H3_ST6, H4_ST2, H4_ST5, and H4_ST6 cannot be rejected.

The results brought many interesting findings triggering a discussion. The COVID-19 crisis is considered intensive by $72.2 \%$ of the respondents (Czech Republic) and 66.6\% (Slovakia), but not detrimental for the SMEs. The respondents' notions suggest that the impact of the COVID-19 crisis on business activities is minimal: 43.4\% in the Czech Republic and 44.7\% in Slovakia; resulting in a discontinuation of business activities due to a low market demand: $35.8 \%$ in the Czech Republic and 36.9\% in Slovakia; resulting in the cancellation of orders by customers: $20.8 \%$ in the Czech Republic and 18.4\% in Slovakia. At the same time, according to Dvorsky et al. (2019), the loss of customers is one of the most serious sources of market risk for SMEs. Due to the COVID-19 crisis, the respondents expect an interannual drop in sales: up to 10\% (27.2\% in the Czech Republic and 25.6\% in Slovakia); from 11\% to 20\% 
(17.5\% in the Czech Republic and 14.1\% in Slovakia); from 21\% to 30\% (21.7\% in the Czech Republic and $20.9 \%$ in Slovakia); from 31\% to $40 \%$ (12.8\% in the Czech Republic and $15.6 \%$ in Slovakia); from $41 \%$ to $50 \%$ (7.2\% in the Czech Republic and 10.6\% in Slovakia) and more than $51 \%$ (13.6\% in the Czech Republic and $13.1 \%$ in Slovakia). This relatively positive opinion could stem from the trust in the national measures adopted in order to ensure support of business activities in both countries. SMEs had not experienced pandemic crises such as COVID-19 before; therefore, impact scenarios from the past that could be utilized with a certain time lapse are non-existent. The recent Severe Acute Respiratory Syndrome (SARS) pandemic in 2002 - 2004 did not have such a big global impact as COVID-19. The negative effects of pandemic crises perceived by entrepreneurs also depend on the time during which business activities are stopped, restricted, or otherwise compromised. Business dissolution, bankruptcy or a complete change of business activities due to the COVID-19 crisis would probably also evoke different views. Based on the respondents' answers, it can be assumed that entrepreneurs do not worry about business dissolution or bankruptcy, despite the intense negative effects of the COVID-19 crisis.

61.4\% of the respondents in the Czech Republic and 59.7\% in Slovakia agree with the claim that they are able to manage financial risk during the COVID-19 crisis (A1+A2). $35.8 \%$ of the respondents in the Czech Republic and 36.3\% in Slovakia agree with the claim that the importance of personnel risk in connection with SMEs' activities was reduces during the COVID-19 pandemic.

Economic measures adopted in order to help overcome the COVID-19 crisis are considered adequate by $47.2 \%$ of the Czech and $43.8 \%$ of the Slovak respondents. $40.0 \%$ of the Czech and $30 \%$ of the Slovak respondents agree that these economic measures adopted in order to overcome the COVID-19 crisis will help businesses survive. Currently, it is very difficult to assess the overall impact of the COVID-19 crisis on countries' economies and the adequacy of the restrictions on businesses and the society, as the situation keeps evolving every day and the crisis is not over. This makes the quantification of the restrictive measures and the evaluation of their effectivity for individual sectors and for the economy as a whole more difficult. In both countries, the most negatively affected industries are services and manufacturing, which is stagnating. Some enterprises have completely stopped production for a definite period of time, and many others have international business ties, which significantly affects their future direction. This is one of the reasons why it would be appropriate to evaluate the perception of the economic measures adopted by the government based on the size and type of the business, as well as their differentiation by business sectors. It also provides a topic for further research that will be segment-oriented, with the aim of discovering how sensitive individual SME segments are to the impact of the COVID-19 crisis, and thus set segment-based crisis scenarios for the future. Macroeconomic experts suggest differentiated impacts of the crisis based on individual segments as well. It is expected that travel, services, accommodation, and non-foods retail will experience the biggest decline. The food industry, pharmaceuticals, and consumer chemistry will experience the least negative impact of the crisis. At the same time, the crisis has prompted many businesses to search for new business opportunities.

It is also interesting to see the shift in the perception of different types of business risk. The perception of financial and personnel risks shifted significantly between the time before and after the crisis. It is logical, although financial risk was significant in the pre-crisis era as well (e.g. the case study from Ajaz Khan et al. (2019) in the SR and CR service firms, Štefko et al. (2020) in the Slovak Spa Industry etc.). During a crisis, the finances take the biggest toll, given the reduction of production and sales, disruption of supply chains, change in demand structures as well as employment processes. Small entrepreneurs who depend on regular sales and have small financial reserves and also a limited access to external financing sources are those fearing financial risk the most, as it can mean dissolution of their businesses. Personnel risk appeared to have been more significant before rather than during the crisis, mainly because in many companies, a large part of the workforce has not been utilized during the crisis, therefore, special work modes were created 
where possible (ICT, services, consulting firms, etc.). Mass layoffs became quite frequent, especially in production. The unused workforce resulting from the reduction of production or a halt of processes in the services sector often presented a burden for the companies. To eliminate mass layoffs and to limit the enormous growth in unemployment rate, both Czech Republic and Slovakia created special mechanisms with the aim of prolonging this critical state. Legal risk was not among the three most significant business risks during the crisis, while Slovak entrepreneurs' notions towards legal risk were different before the crisis. This is because legislation is part of the legal system that needs to be harmonized and adapted to the established policies and strategic targets of the state, which is a long-term process. However, specific government and legislative processes came first when handling any emergency measures during the crisis.

\section{CONCLUSION}

The global COVID-19 crisis has affected the business sector in all countries. Even after the crisis ends, the economy cannot be expected to quickly return to its normal state. Shopping habits, manufacturing methods, ways of traveling or working have changed. This will affect the future functioning of the economy. National governments have begun their active support of the business sector, although the level of their influence on the further problem-free functioning of the segment differs significantly. Experts do not possess enough information to form a qualified assessment of the COVID-19 pandemic's impact on countries' economies. Relevant institutions managing the support of the business environment are unable to prepare system scenarios for individual sectors and individual firms in such a short amount of time, as they lack necessary data. This study reflects these facts, trying to bring essential information on how SMEs perceive these risks.

The aim of the study was to evaluate the impact of the COVID-19 crisis on entrepreneurs' notions towards selected business risks in the SME segment. The comparison of entrepreneurs' notions suggests that entrepreneurs consider market risk, financial risk, and personnel risk the most significant business risks both before and during the COVID-19 crisis in the SME segment in the Czech Republic. The biggest differences were apparent especially in the perception of financial risk and personnel risk. Before the COVID-19 crisis, financial risk was considered one of the three most significant risks by $35.7 \%$ of SMEs in the Czech Republic and by 35.3\% in Slovakia. During the COVID-19 crisis, however, these numbers increased 53.6\% in the Czech Republic and 59.7\% in Slovakia. Before the COVID-19 crisis, personnel risk was considered one of the three most significant risks by $67.8 \%$ of SMEs in the Czech Republic and by $62.8 \%$ in Slovakia. During the COVID-19 crisis, it is only $27.2 \%$ of SMEs in the Czech Republic and $29.4 \%$ of SMEs in Slovakia. Legal risk was not among the three most significant business risks during the crisis, while Slovak entrepreneurs' notions towards legal risk were different before the crisis. Despite the representative sample of 1502 SMEs, it is important to re-verify entrepreneurs' notions in the Czech and Slovak business environment using a larger sample of respondents as time progresses, as the COVID-19 crisis has not yet ended and the economy's return back to normal will not be easy. This can also alter the SMEs' priorities regarding business risk. The recent excess of labor following mass layoffs can result in a future shortage of necessary qualified workforce in individual sectors, as well as in new, emerging enterprises that use innovative processes. Further anomalies due to the impact of the recession on the business sector are not out of question. National governments should play a role in creating effective crisis scenarios for the economy's future growth, as well as setting up appropriate mechanisms for the business environment development and the elimination of negative impacts resulting from the COVID-19 crisis. The research results present a valuable platform for the creators of policies and regional and national strategic development plans, as well as for experts and institutions dealing with support systems for SMEs and business environment development. The study provides valuable research topics, as well as basis for the 
creation of national and international benchmarking indicators enabling the comparison of individual aspects of business systems among countries and thus discover discrepancies and search for optimal possibilities of reducing regional and national economic disparities significantly enhanced by the COVID19 crisis.

\section{ACKNOWLEDGEMENT}

The research was supported by the Research and Development Agency GAAA under the contract No. 21/2020: "Management, business risk and the firm bankruptcy in the segment of SMEs".

\section{REFERENCES}

Abebe, G., Bundervoet, T., \& Wieser, Ch. (2020). Monitoring COVID-19 Impacts on Firms in Ethiopia: Results from a High-Frequency Phone Survey of Firms. World Bank. https://doi.org/10.1596/33766

Adair, P., \& Adaskou, M. (2018). The capital structure of mature French SMEs and impact of the great recession: A dynamic panel data analysis (2002-2010). Economics, Management and Sustainability, 3(2), 60-75. doi:10.14254/jems.2018.3-2.5

Agresti, A. (1992). A survey of exact inference for contingency tables. Statistical Science, 7(1), 131-153. doi:10.1214/ss/1177011454

Åslund. A. (2020). Responses to the COVID-19 crisis in Russia, Ukraine, and Belarus. Eurasian Geography and Economics, 1-14. https://doi.org/10.1080/15387216.2020.1778499

Almunia, Miguel, Monica Martinez-Bravo and Carlos Sanz. (2020). The Political Consequences of the Covid-19 Crisis. AEA RCT Registry. June 26. https://doi.org/10.1257/rct.6084-1.0.

Alves, J. C., Lok, T. Ch., Luo, Y. B., \& Hao, W. (2020). Crisis Management for Small Business during the COVID-19 Outbreak: Survival, Resilience and Renewal Strategies of Firms in Macau. https://doi.org/10.21203/rs.3.rs$34541 / \mathrm{v} 1$

Chai, B.F., \& Sikandar Mirza, S. (2019). Political association, managerial power heterogeneity, and corporate risk-taking in China, Economic Research-Ekonomska Istrą̌ivanja, 32(1), 1373-1393, https://doi.org/ 10.1080/1331677X.2019.1634613

Daniel, M., Rodríguez, C., \& Schmidt-Padilla, C. (2020). Improving Bureaucratic Effectiveness during the COVID-19 Crisis. AEA RCT Registry. May 13. https://doi.org/10.1257/rct.5827-1.0.

Didier, T., Huneeus, F., Larrain, M., \&Schmukler, S. L. (2020). Financing firms in hibernation during the COVID-19 Pandemic. World Bank. https://doi.org/10.1596/33611

Dvorský, J., Petráková, Z., \& Polách, J. (2019). Assessing the market, financial and economic risk sources by Czech and Slovak SMEs. International Journal of Entrepreneurial Knowledge, 7(2), 30-40. https://doi.org/10.2478/ijek2019-0008

Enamul Hoque, M.,, Wah, L.S., \& Shah Zaidi, M.A. (2019). Oil price shocks, global economic policy uncertainty, geopolitical risk, and stock price in Malaysia: Factor augmented VAR approach, Economic Research-Ekonomska Istrą̌ivanja, 32(1), 3700-3732, https://doi.org/10.1080/1331677X.2019.1675078

Fontrodona, J., \& Muller, P. (2020). Reforzar la integridad empresarial ante la crisis del Covid-19 (Strengthening Business Integrity in the Face of the COVID-19 Crisis) (April 8, 2020). Available at SSRN: https://ssrn.com/abstract=3571706 or http://dx.doi.org/10.2139/ssrn.3571706

Goodman, L. A. (1970). The multivariate analysis of qualitative data: Interactions among multiple classifications. Journal of the American Statistical Association, 65(329), 226-256. doi:10.1080/01621459.1970.10481076

Gray, R. S. (2020). Agriculture, transportation, and the COVID-19 crisis. Canadian Agricultural Economics Society, 1-5. https://doi.org/10.1111/cjag.12235

Hudson, D. S. (2020a). Chapter 5. The economic, social and environmental impacts of COVID 19. In: Hudson, D.S. (ed). Oxford: Goodfellow Publishers

Hudson, D. S. (2020b) COVID-19 and Travel. Oxford: Goodfellow Publishers http://dx.doi.org/10.23912/9781911635703-4387 
Khan, K., A., Çera, G., \& Nétek, V. (2019). Perception of the Selected Business Environment Aspects by Service Firms. Journal of Tourism and Services, 10(19), 111-127. https://doi.org/10.29036/jots.v10i19.115

Khan, K. A., Dankiewicz, R., Kliuchnikava, Y., \& Oláh, J. (2020). How Do Entrepreneurs Feel Bankruptcy? International Journal of Entrepreneurial Knowledge, 8(1), 89-101. https://doi.org/10.37335/ijek.v8i1.103

Michie, J. (2020). The covid-19 crisis - and the future of the economy and economics. International Review of Applied Economics, 301-303. https://doi.org/10.1080/02692171.2020.1756040

Levashenko, A., \& Koval, A. (2020). Measures of Financial and Non-Financial Support to Small and Medium-sized Enterprises (SMEs) in the Wake of COVID-19 (May 17, 2020). Monitoring of Russia's Economic Outlook. Trends and Challenges of Socio-economic Development. Moscow. IEP, 9, 7-10. https://ssrn.com/abstract=3629597 or http://dx.doi.org/10.2139/ssrn.3629597

Lu, Y., Wu, J., Peng, J., \& Lu, L. (2020). The perceived impact of the Covid-19 epidemic: evidence from a sample of 4807 SMEs in Sichuan Province, China, Environmental Hazards. https://doi.org/10.1080/17477891.2020.1763902

Morrison, E., \& Saavedra, A. (2020). Bankruptcy's Role in the COVID-19 Crisis (April 7, 2020). Columbia Law and Economics Working Paper No. 624, Available at SSRN: https://ssrn.com/abstract $=3567127$ or http://dx.doi.org/10.2139/ssrn.3567127

Mostenska, T., Bilan, Y. \& Mostenska, T. G. (2015). Risk management as a factor ensuring enterprises' economic security. Actual Problems of Economics, 170(8), 193-203.

Murshed, S. M. (2020). Capitalism and COVID-19: Crisis at the Crossroads. Peace Economics, Peace Science and Public Policy. https://doi.org/10.1515/peps-2020-0026

Oluyede, B. O. (1994). A modified chi square test of independence against a class of ordered alternatives in an $\mathrm{r} \times \mathrm{c}$ contingency table. Canadian Journal of Statistics, 22(1), 75-87. doi:10.2307/3315824

Peček, B., \& Kovačič, A. (2019). Methodology of monitoring key risk indicatorsю Economic Research-Ekonomska Istraživanja, 32(1), 3485-3501, https://doi.org/10.1080/1331677X.2019.1658529

Prohorovs, A. (2020). Getting Ready for Recession: How SMEs Prepared for Covid-19 Pandemic and Economic Recession (May 7, 2020). Forbes (Latvian edition) No. 11, May 2020, pp. 46-49. https://ssrn.com/abstract=3596611 or http://dx.doi.org/10.2139/ssrn.3596611

Rathore, U., \& Khanna, S. (2020). From Slowdown to Lockdown: Effects of the COVID-19 Crisis on Small Firms in India (May 31, 2020). Available at SSRN: https://ssrn.com/abstract $=3615339$ or http://dx.doi.org/10.2139/ssrn.3615339

Redmond, P., \& McGuinness, S. (2020). Essential Employees during the Covid-19 Crisis. The Economic and Social Research Institute, 1-10. ISBN 978-0-7070-0520-1

Staszkiewicz, P., \& Szelagowska, A. (2019). Ultimate owner and risk of company performance. Economic ResearchEkonomska Istraživanja, 32(1), 3795-3812, https://doi.org/10.1080/1331677X.2019.1678499

Štefko, R., Jenčová, S., \& Vašaničová, P. (2020). The Slovak Spa Industry and Spa Companies: Financial and Economic Situation. Journal of Tourism and Services, 20(11), 28-43. doi: 10.29036/jots.v11i20.137

Wallis, S. (2013). Z-squared: The origin and application of $\chi 2$. Journal of Quantitative Linguistics, 20(4), 350-378. doi:10.1080/09296174.2013.830554

Wang, Y., Hong, A., Li, X., \& Gao, J. (2020). Marketing innovations during a global crisis: A study of China firms' response to COVID-19. Journal of Business Research, 116, 214-220. https://doi.org/10.1016/j.jbusres.2020.05.029

Wang, S. S., Goh, J. R., Sornette, D., Wang, H., \& Yang, E. Y. (2020). Government Support for SMEs in Response to COVID-19: Theoretical Model Using Wang Transform (June 12, 2020). https://ssrn.com/abstract=3608646

WTO (2020). Helping SMEs Navigate the COVID-19 Crisis. WTO Working Papers, No. 2020/08, WTO, Geneva, pp. 1-8. https://doi.org/10.30875/2e95e9bf-en. 